\title{
Normative Nasalance Scores for Middle-Aged and Elderly Speakers of Brazilian Portuguese
}

\author{
Viviane Cristina de Castro Marino ${ }^{a}$ Vanessa Moraes Cardoso ${ }^{a} \quad G^{\prime}$ illian de Boer ${ }^{b}$ \\ Jeniffer de Cássia Rillo Dutka ${ }^{c}$ Eliana Maria Gradim Fabbron ${ }^{a}$ Tim Bressmann ${ }^{b}$ \\ ${ }^{a}$ Speech-Language and Audiology Department, School of Philosophy and Sciences, São Paulo State University \\ (UNESP), Marília, Brazil; ${ }^{b}$ Department of Speech-Language Pathology, University of Toronto, Toronto, ON, Canada; \\ 'Speech-Language and Audiology Department, Faculdade de Odontologia de Bauru and Graduate Programs at the \\ Hospital de Reabilitação de Anomalias Craniofaciais, Universidade de São Paulo (USP), Bauru, Brazil
}

\section{Keywords}

Nasometry $\cdot$ Nasalance scores $\cdot$ Nasometer $\cdot$ Brazilian

Portuguese $\cdot$ Cleft palate $\cdot$ Speech

\begin{abstract}
Objectives: This study establishes normative nasalance values for middle-aged and elderly Brazilian Portuguese-speakers and investigates age and gender effects across the life span. Methods: Nasalance scores were obtained from 62 middle-aged ( $45-59$ years) and 60 elderly (60-79 years) participants with normal speech for 3 nonnasal, 1 phonetically balanced, and 2 nasal-loaded test sentences using the Nasometer II 6400. The data were combined with a published data set of 237 speakers in 4 groups: children (5-9 years), adolescents (10-19 years), young adults (20-24 years), and mature adults (25-35 years). A repeated-measures analysis of variance was used to investigate differences between the stimuli by gender and age groups. Results: There were statistically significant effects of stimulus, gender, and age group, as well as a stimulus-age group interaction effect and a gender-age group interaction effect. The females' mean nasalance scores were higher than those of the males. The mean nasalance scores for the child, adolescent, and young and mature adult speakers were significantly lower than
\end{abstract}

those for the elderly speakers, and the children's scores were significantly lower than those of the middle-aged speakers. Conclusion: Higher nasalance scores among middle-aged and elderly speakers may indicate physiological changes affecting oral-nasal balance in speech across the life span.

(c) 2018 S. Karger AG, Basel

\section{Introduction}

The assessment of oral-nasal balance disorders is a crucial task for speech-language pathologists. Hypernasality, hyponasality, and mixed nasality can manifest in a variety of clinical populations. Hypernasality results from anatomical and/or functional conditions compromising velopharyngeal function, while hyponasality is usually due to nasal or nasopharyngeal blockages impacting the transmission of nasal acoustic energy [1]. Clinicians use perceptual and quantitative measures to assess the presence and degree of oral-nasal balance disorders [2-4]. Quantitative instrumental measures serve to corroborate and augment the perceptual assessment $[3,5]$.

This study was conducted at the School of Philosophy and Sciences, São Paulo State University (UNESP), Marília, Brazil.

\section{KARGER}

(c) 2018 S. Karger AG, Basel

E-Mail karger@karger.com

www.karger.com/fpl
Viviane Cristina de Castro Marino, $\mathrm{PhD}$

Speech-Language and Audiology Department, School of Philosophy and Sciences São Paulo State University (UNESP), Rua Hygino Muzzi Filho 737

Marília, SP 17.525-000 (Brazil)

E-Mail vivianemarino2@yahoo.com.br 
The most frequently employed acoustic measure for assessing oral-nasal balance disorders and monitoring treatment outcomes is nasometry [6-8], usually with a Nasometer (Kay Pentax, Lincoln Park, NJ, USA) [9]. The system is noninvasive and provides a nasalance score, which is the ratio of nasal acoustic energy to the sum of nasal plus oral acoustic energy in speech, expressed as a percentage $([\mathrm{N} /(\mathrm{N}+\mathrm{O})] \times 100 \%)[10]$. Clinically, high nasalance scores for oral passages usually correlate with perceptual impressions of hypernasality, while low nasalance scores for nasal sentences correlate with hyponasality [3].

Nasalance scores have been reported for children, adolescents, and adults presenting with a variety of conditions including cleft palate [11], hearing impairment [12], neurogenic dysarthria $[13,14]$, and chronic rhinosinusitis [15]. Nasalance scores obtained from clinical populations are compared with normative scores for a particular language [16]. Nasalance may vary between different languages; therefore, establishing such norms is important for the assessment of oral-nasal balance $[17,18]$.

Normative nasalance scores have been reported for numerous languages including English [17, 19, 20], Finnish [21], Brazilian Portuguese [22, 23], Japanese [24, 25], Flemish [26-28], Hungarian [29], and Swedish [9], to name but a few. However, most of the available normative nasalance data reported to date have been acquired from child or young adult speakers $[9,17,18,20-27,29]$. Other studies recruited participants up to the age of 63 years [19] and even 80 years [28], but did not report the normative values separated by age groups. The available norms for older speakers are limited to Canadian English and French [30], and to middle-aged (46-53 years) Flemish females [31]. Nasalance norms for middle-aged and older speakers are not available for Brazilian Portuguese. In Brazilian Portuguese, vowels are nasalized not only by assimilation (as in English) but also phonemically, that is, without the production of a nasal phoneme before or after the vowel [32]. Norms for Brazilian Portuguese would contribute to the clinical assessment of older adults with oral-nasal balance disorders.

Existing research on the effects of age on nasalance scores has shown that children have lower nasalance scores than young adults [22, 27, 29, 30] and older adults [30]. Younger children have lower nasalance scores than older children [9, 33]. However, D'haeseleer et al. [31] found that young and middle-aged women produced similar nasalance scores for connected speech. Marino et al. [23] did not find any statistical main effect of age on nasalance scores. However, the authors observed an age-

Nasalance Scores for Older Speakers of Brazilian Portuguese stimulus interaction, whereby children scored 2-4 points lower for oral passages than young and mature adults [23]. Few studies have investigated the nasalance scores of geriatric speakers. In a study including subjects up to 80 years of age, Hutchinson et al. [34] found that young adults (18-38 years) had lower nasalance scores than adults over the age of 50 years, which they attributed to an age-related deterioration of velopharyngeal sphincter function. However, the instrument used by Hutchinson et al. [34] was the TONAR II, the precursor of the Nasometer, and so the results may not be comparable. Furthermore, in a study based on airflow measurements, Hoit et al. [35] found no evidence of such age-related deterioration. The first and main goal of the present study was to investigate possible changes in oral-nasal balance with middle and older age.

An additional question of this study was the possible effect of gender on the nasalance scores of middle-aged and elderly speakers. The potential effect of gender on nasalance scores remains an open question. A number of studies have not found statistically significant effects of gender on nasalance scores for children or adult speakers $[7,9,17,22,24,28,29,36-41]$. However, other studies have reported slightly higher nasalance scores for female speakers, particularly when the texts contained nasals consonants $[19,20,23,25,27,30,42,43]$. In older age, females were reported to have higher nasalance scores than their male counterparts [34]. It was therefore the second goal of the current study to provide additional information on the effect of gender on nasalance scores in middle-aged and elderly speakers.

Two research hypotheses were formulated to guide the present study. Hypothesis 1 posits that based on the agerelated trends reported in the literature $[22,27,29,30]$ and the only previous study on nasalance values in geriatric speakers [34], it was expected that middle-aged and elderly speakers would have higher nasalance scores than children and younger adults. Hypothesis 2 postulates that based on reported gender differences in nasalance among older speakers using the TONAR II [34], it was expected that middle-aged and elderly female speakers would have higher nasalance scores than male speakers in these age ranges.

\section{Methods}

The equipment, recording procedures, stimuli, and laboratory settings used to collect nasalance values for the middle-aged and elderly participants were the same as those used to establish nasalance norms for younger (children, adolescents, young adults, and mature adults) Brazilian Portuguese-speakers [23].

Folia Phoniatr Logop 2018;70:82-89 


\section{Participants}

One hundred and thirty-two participants between the ages of 45 and 78 years were recruited from the local community. The participants completed a short questionnaire to screen for neurological, respiratory, laryngeal, auditory, and congenital conditions. To screen for presbycusis, pure-tone hearing evaluations were conducted. Subjects below 60 years of age were included if the mean pure-tone thresholds for $0.5,1$, and $2 \mathrm{kHz}$ for both ears were within $25 \mathrm{~dB}$. Subjects aged 60 years and older were included if the mean pure-tone thresholds for $0.5,1$, and $2 \mathrm{kHz}$ were within $25 \mathrm{~dB}$ for one ear and up to $40 \mathrm{~dB}$ for the other ear. After applying the exclusion criteria, data were collected from 122 (62 middle-aged [ $45-59$ years] and 60 elderly [60-79 years]) participants. The participants spoke the Brazilian Portuguese dialect typical for the mid-western region of São Paulo State as their first and only language. The middle-aged group consisted of $32 \mathrm{fe}-$ males and 30 males (52.10 years [SD 3.75]), and in the elderly group, there were 31 females and 29 males (68.40 years [SD $5.33])$.

\section{Speech Stimuli}

Three of the stimulus sentences were from Trindade et al. [22], namely, the oral ZOO-BR, the low-pressure oral ZOO2-BR (loaded with liquid consonants), and the nasal-loaded NASAL-BR. Four additional stimulus sentences were recently developed for Brazilian Portuguese-speakers [23]. They included (1) an oral passage Dudu no zoológico (Dudu at the zoo; $82 \%$ oral pressure consonants), (2) an alternative oral passage Dudu no bosque (Dudu at the park; $82 \%$ oral pressure consonants), which was syntactically and semantically less complex than Dudu no zoológico, (3) an oralnasal passage O cãozinho Totó (Toto the puppy) (15.9\% nasal phonemes), and (4) a nasal-loaded passage O nenê (the baby) (47.5\% nasal consonants) [23].

The four more recently developed stimuli [23] were created for use with younger children or older subjects with poor reading skills. In order to be able to use the same stimuli with patients of various ages, educational levels, and cognitive functioning, it was important to use syntactically and semantically less complex material.

\section{Recording Procedures}

Nasalance scores were obtained using a Nasometer II 6400 (Kay Pentax) in a sound-treated laboratory. The Nasometer was calibrated prior to each day's data collection according to the manufacturer's instructions. The participants read the stimuli at a comfortable pitch and loudness. To assess test-retest reliability, the stimuli were read twice in the following order: Dudu no zoo, simplified Dudu no bosque, O cãozinho Totó, O nenê, ZOO-BR, ZOO2$\mathrm{BR}$, and NASAL-BR.

\section{Data Analysis}

The data were analyzed using NCSS version 8.0 (NCSS LLC, Kaysville, UT, USA). The mean nasalance scores and the test-retest variability were calculated first. Then, in order to assess the effect of age on normative nasalance scores across the life span, the data collected in this study were combined with a preexisting data set. The current nasalance scores from the 62 middle-aged (45-59 years) and 60 elderly (60-79 years) participants were assessed together with those from 237 speakers with complete data sets from Marino et al. [23]: 57 children (5-9 years, 30 females), 61 adoles- cents (10-19 years, 24 females), 58 young adults (20-24 years, 25 females), and 64 mature adults (25-35 years, 32 females).

As the participants in the study by Marino et al. [23] read the stimuli only once and the speakers of the current study read the stimuli twice, the comparisons between the data sets were based on the middle-aged and elderly groups' first enunciations. The effects of age and gender on nasalance scores were assessed using a repeated-measures analysis of variance (ANOVA). "Stimulus" (7 levels) was entered as a within-group factor, and "age group" (6 levels) and "gender" (2 levels) were entered as between-group factors. Where sphericity was violated, the Greenhouse-Geisser adjustment was used. The $p$ value for significance was set at 0.05 . For the post hoc comparisons, unpaired $t$ tests were run with the $p$ value adjusted for the number of comparisons (Holm-Bonferroni method) [44].

\section{Results}

The mean nasalance scores and standard deviations of the 7 stimuli for the middle-aged and elderly subjects are shown in Table 1. The test-retest variability was assessed by calculating the absolute difference between the middle-aged and the elderly participants' first and second enunciation for each stimulus. The mean difference in nasalance scores between enunciations was 1.79 (SD 1.67) for the middle-aged group and 1.83 (SD 1.64) for the elderly group. The cumulative frequencies, along with the means and standard deviations of these differences, are shown in Tables 2 and 3.

\section{Effects of Age and Gender across the Life Span}

The nasalance scores of the first enunciations of the stimuli by the middle-aged and elderly speakers were combined with the data from Marino et al. [23]. A repeated-measures ANOVA was run for 7 stimuli, with 6 age groups and gender as between-group factors. There were significant effects of stimulus $(F(6,2,082)=12,087.12$; $p<0.01)$, age group $(F(5,347)=16.01 ; p<0.01)$, and gen$\operatorname{der}(F(1,347)=15.16 ; p<0.01)$, as well as a stimulusage group interaction effect $(F(30,2,122)=9.96 ; p<0.01)$ and a gender-age group interaction effect $(F(5,347)=$ $2.64 ; p<0.05)$. There were no other interaction effects.

For the main effect of stimulus, post hoc testing showed that the mean nasalance scores (across all 6 age groups and both genders) for the oral stimulus Dudu no zoo (mean 12.16 [SD 5.46]), the simplified oral stimulus Dudu no bosque (mean 12.75 [SD 5.73]), ZOO-BR (mean 11.99 [SD 5.57]), and ZOO2-BR (mean 14.30 [SD 7.08]) were significantly lower than that for the balanced oral-nasal stimulus $O$ cãozinho Totó (mean 27.61 [SD 5.48]), which was in turn significantly lower than that for the nasal 
Table 1. Mean nasalance scores (\%) and SDs from 2 enunciations of 7 stimuli by Brazilian speakers, according to their age group and gender $(n=122)$

\begin{tabular}{|c|c|c|c|c|c|c|c|c|}
\hline \multirow[t]{3}{*}{ Stimuli } & \multicolumn{4}{|c|}{ Middle-aged $(n=62)$} & \multicolumn{4}{|c|}{ Elderly $(n=60)$} \\
\hline & \multicolumn{2}{|c|}{$\begin{array}{l}\text { male } \\
(n=32)\end{array}$} & \multicolumn{2}{|c|}{$\begin{array}{l}\text { female } \\
(n=30)\end{array}$} & \multicolumn{2}{|c|}{$\begin{array}{l}\text { male } \\
(n=31)\end{array}$} & \multicolumn{2}{|c|}{$\begin{array}{l}\text { female } \\
(n=29)\end{array}$} \\
\hline & M & $\mathrm{SD}$ & M & SD & $\mathrm{M}$ & SD & M & $\mathrm{SD}$ \\
\hline Oral passage (Dudu no zoo) & 14.44 & 6.65 & 14.30 & 4.29 & 17.34 & 7.22 & 17.02 & 6.87 \\
\hline Oral-simplified (Dudu no bosque) & 14.19 & 6.49 & 15.37 & 6.12 & 16.69 & 8.82 & 16.98 & 7.03 \\
\hline $\mathrm{ZOO}-\mathrm{BR}$ & 12.48 & 6.53 & 15.47 & 5.43 & 15.62 & 7.46 & 17.89 & 6.82 \\
\hline $\mathrm{ZOO} 2-\mathrm{BR}$ & 16.64 & 7.40 & 18.12 & 7.66 & 20.38 & 9.52 & 21.34 & 9.04 \\
\hline Oronasal passage (O cãozinho Totó) & 27.98 & 6.49 & 30.57 & 4.78 & 30.72 & 6.28 & 32.23 & 7.82 \\
\hline Nasal passage $(\mathrm{O}$ nenê $)$ & 49.72 & 5.86 & 51.67 & 5.09 & 50.26 & 7.08 & 52.82 & 8.07 \\
\hline NASAL-BR & 48.86 & 6.10 & 50.75 & 5.42 & 51.19 & 6.11 & 52.05 & 8.31 \\
\hline
\end{tabular}

Table 2. Cumulative frequencies (counts/percentages) and means of test-retest differences for middle-aged speakers

\begin{tabular}{|c|c|c|c|c|c|c|c|}
\hline \multirow{2}{*}{$\begin{array}{l}\text { Nasalance score } \\
\text { difference }\end{array}$} & \multicolumn{4}{|l|}{ Oral } & \multirow{2}{*}{$\begin{array}{l}\text { Oronasal } \\
\text { (O cãozinho } \\
\text { Totó) }\end{array}$} & \multicolumn{2}{|l|}{ Nasal } \\
\hline & $\begin{array}{l}\text { Dudu no } \\
\text { zoo }\end{array}$ & $\begin{array}{l}\text { Dudu no } \\
\text { bosque }\end{array}$ & ZOO-BR & $\mathrm{ZOO} 2-\mathrm{BR}$ & & Onenê & NASAL-BR \\
\hline $0-3$ & $58 / 93.55$ & $53 / 85.48$ & $57 / 91.94$ & $52 / 83.87$ & $57 / 91.94$ & $58 / 93.55$ & $55 / 88.71$ \\
\hline$\leq 4$ & $58 / 93.55$ & $58 / 93.55$ & $59 / 95.16$ & $55 / 88.71$ & $59 / 95.16$ & $59 / 95.16$ & $56 / 90.32$ \\
\hline$\leq 5$ & $59 / 95.16$ & $59 / 95.16$ & $62 / 100$ & $56 / 90.32$ & $61 / 98.39$ & $59 / 95.16$ & $58 / 93.55$ \\
\hline$\leq 6$ & $60 / 96.77$ & $59 / 95.16$ & & $57 / 91.94$ & $62 / 100$ & $61 / 98.39$ & $60 / 96.77$ \\
\hline$\leq 7$ & $61 / 98.39$ & $62 / 100$ & & $59 / 95.16$ & & $62 / 100$ & $61 / 98.39$ \\
\hline$\leq 8$ & $61 / 98.39$ & & & $60 / 96.77$ & & & $62 / 100$ \\
\hline$\leq 9$ & $62 / 100$ & & & $62 / 100$ & & & \\
\hline Mean difference & 1.35 & 1.94 & 1.53 & 2.19 & 1.95 & 1.65 & 1.9 \\
\hline $\mathrm{SD}$ & 1.75 & 1.69 & 1.34 & 2.21 & 1.22 & 1.45 & 1.78 \\
\hline
\end{tabular}

Bold font indicates the cutoff at which $90 \%$ of the nasalance score differences were captured.

stimulus $O$ nenê (mean 49.73 [SD 5.68]) and NASAL-BR (mean 49.72 [SD 5.52]). In addition, the mean nasalance score for the low-pressure oral stimulus ZOO2-BR was significantly higher than the scores for the remaining oral stimuli ( $p$ value for significance $=0.05 / 21=0.00238$ ) .

For the main effect of age group, post hoc testing showed that the mean nasalance scores (across both genders and the 7 stimuli) for the children (mean 23.51 [SD 17.90]), adolescents (mean 23.95 [SD 17.05]), young adults (mean 24.23 [SD 17.20]), and mature adults (mean 24.45 [SD 16.93]) were significantly lower than that for the elderly speakers (mean 29.37 [SD 16.63]). In addition, the children had significantly lower scores than the mid- dle-aged speakers (mean 27.11 [SD 16.66]) ( $p$ value for significance $=0.05 / 15=0.00333$ ).

For the main effect of gender, the mean nasalance score (across all 6 age groups and 7 stimuli) for females (mean 26.39 [SD 17.15]) was significantly higher than that for males (mean 24.53 [SD 17.14]; $p<0.01$ ).

To assess the stimulus-age group interaction effect, post hoc $t$ tests were run comparing the 6 age groups within each of the 7 stimuli. The mean nasalance scores by age group and stimulus are displayed in Table 4 . Post hoc testing showed that for the oral stimulus Dudu no zoo, the nasalance scores for the younger groups were significantly lower than those for both the middle-aged and the 
Table 3. Cumulative frequencies (counts/percentages) and means of test-retest differences for elderly speakers

\begin{tabular}{|c|c|c|c|c|c|c|c|}
\hline \multirow{2}{*}{$\begin{array}{l}\text { Nasalance } \\
\text { score } \\
\text { difference }\end{array}$} & \multicolumn{4}{|l|}{ Oral } & \multirow{2}{*}{$\begin{array}{l}\text { Oronasal } \\
\text { O cãozinho } \\
\text { Totó }\end{array}$} & \multicolumn{2}{|l|}{ Nasal } \\
\hline & $\begin{array}{l}\text { Dudu no } \\
\text { zoo }\end{array}$ & $\begin{array}{l}\text { Dudu no } \\
\text { bosque }\end{array}$ & $\mathrm{ZOO}-\mathrm{BR}$ & ZOO2-BR & & O nenê & NASAL-BR \\
\hline $0-3$ & $50 / 83.33$ & $50 / 83.33$ & $53 / 88.33$ & $47 / 78.33$ & $51 / 85.00$ & $55 / 91.67$ & $56 / 93.33$ \\
\hline$\leq 4$ & $52 / 86.67$ & $56 / 93.33$ & $56 / 93.33$ & $49 / 81.67$ & $55 / 91.67$ & $60 / 100$ & $59 / 98.33$ \\
\hline$\leq 5$ & $59 / 98.33$ & $58 / 96.67$ & $57 / 95.00$ & $56 / 93.33$ & $57 / 95.00$ & & $60 / 100$ \\
\hline$\leq 6$ & $59 / 98.33$ & $59 / 98.33$ & $60 / 100$ & $56 / 93.33$ & $57 / 95.00$ & & \\
\hline$\leq 7$ & $60 / 100$ & $59 / 98.33$ & & $58 / 96.67$ & $59 / 98.33$ & & \\
\hline$\leq 8$ & & $60 / 100$ & & $60 / 100$ & $60 / 100$ & & \\
\hline Mean difference & 1.82 & 1.95 & 1.82 & 2.28 & 2 & 1.5 & 1.47 \\
\hline $\mathrm{SD}$ & 1.74 & 1.67 & 1.53 & 2.1 & 1.73 & 1.21 & 1.26 \\
\hline
\end{tabular}

Bold font indicates the cutoff at which $90 \%$ of the nasalance score differences were captured.

Table 4. Mean nasalance scores (\%) and SDs of 7 stimuli by age group for 359 Brazilian speakers

\begin{tabular}{lccllll}
\hline Stimuli & $\begin{array}{l}\mathrm{G} 1 \\
(n=57)\end{array}$ & $\begin{array}{l}\mathrm{G} 2 \\
(n=61)\end{array}$ & $\begin{array}{l}\mathrm{G} 3 \\
(n=58)\end{array}$ & $\begin{array}{l}\mathrm{G} 4 \\
(n=61)\end{array}$ & $\begin{array}{l}\mathrm{G} 5 \\
(n=62)\end{array}$ & $\begin{array}{l}\mathrm{G} 6 \\
(n=60)\end{array}$ \\
\hline Oral passage & $9.71(3.15)$ & $10.29(3.43)$ & $10.41(3.86)$ & $11.03(4.63)$ & $14.35(5.67)$ & $16.91(6.95)$ \\
Oral-simplified & $10.43(3.8)$ & $11.78(4.16)$ & $11.44(4.44)$ & $11.26(4.54)$ & $14.62(6.26)$ & $16.73(7.57)$ \\
ZOO-BR & $9.1(2.72)$ & $9.98(3.26)$ & $10.37(3.44)$ & $11.52(4.9)$ & $13.9(6.42)$ & $16.81(6.98)$ \\
ZOO2-BR & $9.61(3.42)$ & $11.96(4.58)$ & $12.75(4.96)$ & $13.57(5.5)$ & $17.03(7.48)$ & $20.51(9.05)$ \\
Oronasal passage & $26.59(3.76)$ & $25.75(3.5)$ & $25.96(4.12)$ & $26.34(4.61)$ & $29.32(6.11)$ & $31.55(7.18)$ \\
Nasal passage & $49.78(5.48)$ & $48.72(4.03)$ & $49.37(4.49)$ & $48.55(5.67)$ & $50.53(5.69)$ & $51.4(7.66)$ \\
NASAL-BR & $49.29(4.85)$ & $49.14(4.14)$ & $49.27(4.29)$ & $48.88(5.83)$ & $49.98(5.72)$ & $51.68(7.3)$ \\
\hline
\end{tabular}

The mean nasalance scores for the middle-aged and elderly speakers are based on their first enunciation.

elderly speakers. For the simplified oral stimulus Dudu no bosque, the children's mean nasalance score was lower than the scores for both the middle-aged and the elderly speakers, while the adolescents', young adults', and mature adults' scores were significantly lower than the elderly speakers' score. For ZOO-BR, the scores for the children, adolescents, and young adults were significantly lower than those for the middle-aged and elderly groups, and the mean nasalance score for the mature adult group was significantly lower than that for the elderly speakers. For ZOO2-BR, the children scored significantly lower than the 4 oldest groups (all but the adolescents); the adolescents and young adults had significantly lower scores than the middle-aged and elderly speakers, and the mature adult group's mean nasalance score was lower than the elderly speakers' score. For the balanced oral-nasal $O$ cãozinho Totó, the scores for the 4 youngest groups were significantly lower than the score for the elderly group, and the mean nasalance score for the adolescent group was significantly lower than that for the middle-aged speakers. For the nasal stimulus $O$ nene and NASAL-BR, there were no significant differences in mean nasalance scores between the age groups (for all significant differences, $p$ value $=0.05 /[15 \times 7]=0.000476$ ).

To assess the between-group gender-age interaction effect, two sets of Bonferroni-adjusted post hoc $t$ tests were run. The first tests compared the genders within the 6 age groups and the second compared the 6 age groups separated by gender. When the nasalance scores for the genders within each of the 6 age groups were compared, the difference was only significant for the mature adult group, where females (26.79 [SD 16.90]) scored higher than males (21.88 [SD 16.65]) ( $p$ value for significance $=$ $0.05 / 6=0.0083)$. For the second set of comparisons, 
among females, the mean nasalance scores for the children (mean 23.13 [SD 18.04]) and the adolescents (mean 24.58 [SD 16.99]) were significantly lower than the score for the elderly group (mean 29.96 [SD 16.91]). Among males, the scores for the children (mean 23.30 [SD 17.12]), adolescents (mean 23.08 [SD 17.56]), and young adults (mean 21.88 [SD 16.65]) were significantly lower than the score for the elderly group (mean 28.74 [SD 16.35]) $(p$ value for significance $=0.05 /[15 \times 2]=0.00167)$.

\section{Discussion}

As the vast majority of published normative nasalance values are based on children or young adults, this study first established normative nasalance values for middleaged and elderly Brazilian Portuguese-speakers. The data on test-retest variability were comparable to those previously reported for younger English-speakers [45].

The repeated-measures ANOVA found a significant main effect for stimulus. This effect confirmed the expected differences between the stimuli that can be attributed to the differences in their relative content of nasal sounds. The nasalance scores for the oral stimuli were significantly lower than the score for the balanced oralnasal stimulus, which was in turn significantly lower than the scores for the nasal stimuli. The mean nasalance score for the low-pressure oral stimulus ( $\mathrm{ZOO} 2-\mathrm{BR}$, loaded with low-pressure liquid sounds) was significantly higher than the scores for the other oral stimuli. The same pattern had been found in previous research [23].

Based on previously reported findings $[22,27,29,30$, 34], the first hypothesis stated that middle-aged and elderly speakers would have higher nasalance scores than children and younger adults. The significant main effect for age group confirmed the first hypothesis and demonstrated that the elderly speakers had higher nasalance scores than the children, adolescents, young adults, and mature adults. In addition, the children's nasalance scores were significantly lower than those of the middle-aged speakers. These age differences are consistent with findings previously reported $[19,30,34]$. In the present study, however, there was an age-stimulus interaction effect, whereby the effects of age were limited to the oral and the oral-nasal balanced stimuli. In contrast, Hutchinson et al. [34] and Rochet et al. [30] had no age-stimulus interaction effect, while Seaver et al. [19] found that the effect of age was limited to nasal stimuli (with a weak positive correlation). These differences notwithstanding, the findings from the current study support previous data suggesting

Nasalance Scores for Older Speakers of Brazilian Portuguese increased nasalance scores for older speakers. Among the studies that have discussed the effect of age on nasalance scores, most have highlighted differences between the scores of children and adults, in which children scored lower than adults for oral speech stimuli $[22,46]$ or even for all sentence stimuli (oral, phonetically balanced, and nasal) [29]. These findings have been attributed to the increased cross-sectional area of the nasal cavity in adults compared to children, leading to more nasal resonance and higher nasalance scores across the life span [47]. The same effect could be demonstrated when comparing nasalance scores for younger and older children $[9,33]$.

Higher nasalance scores in older and/or elderly speakers have been attributed to age-related changes in the structure or function of the vocal tract $[30,34]$. Tomoda et al. [48] found that two velopharyngeal muscles (tensor and levator veli palatini) atrophy with age. Based on findings from magnetic resonance imaging, Mahne et al. [49] found that the soft palate decreased in volume. Schötz [50] described general changes in the supralaryngeal system that occur with age (increased length of the vocal tract due to lowering of the larynx in the neck, diminished oral opening due to reduction of the size of the temporomandibular joint, and decreased sensation in the pharynx and soft palate, some of which may affect speech). Investigation of the nasal architecture in young and geriatric populations using acoustic rhinometry has shown that endonasal volumes and minimal cross-sectional areas gradually increase with age [51], probably due to decreased functioning of the nasal mucosa [52]. However, aerodynamic studies to date have failed to show any evidence of change in velopharyngeal competence with healthy aging $[35,53]$.

The second hypothesis stated that middle-aged and elderly female speakers would have higher nasalance scores than middle-aged and elderly male speakers, as reported in previous research [34]. This hypothesis was not confirmed. The significant main effect of gender confirmed that female speakers had higher nasalance scores overall. Across all stimuli and age groups, the females scored 2 mean nasalance points higher than the males. However, when the first gender-age group interaction was examined (effect of gender within age groups), the females only scored significantly higher in the mature adult group. The females of the middle-aged and elderly groups scored numerically higher than their male counterparts, but the difference was not significant $(p=0.27$ and $p=0.45$, respectively). It is not surprising that this effect was not very clear-cut. The research literature is split regarding the evidence for $[20,23,25,27,30,42,43]$ or against gender 
differences in nasalance scores $[7,9,17,22,24,28,29$, 36-41].

Where studies did find higher nasalance scores for females $[20,23,25,27,30,42,43]$, the differences were often attributed to anatomical or physiological differences, although these explanations often remained speculative. Using the Glottal Systems OroNasal device (Glottal Enterprises, Syracuse, NY, USA), Bundy and Zajac [54] found a positive relationship between the higher fundamental frequency in female speakers and transpalatal nasalance, i.e., sound that was transmitted into the nasal passage through the velar tissue of the closed velopharyngeal sphincter. An anatomical difference such as in transpalatal sound transmission would lead to a constant difference in nasalance scores, irrespective of the phonetic content of the stimuli. This explanation fits the results of the present study well, because there were no significant gender-stimulus interaction effects. However, in contrast to the present study's findings, other researchers have found that gender differences were limited to phonetically balanced or nasal stimuli $[20,27,30,43]$.

The second gender-age interaction (effect of age within gender) found for the speakers of Brazilian Portuguese in the present study indicated that the genders followed the same pattern across the ages, with the exception of the young adult group. Young adult men had lower scores than their elderly counterparts, but the young adult females did not. However, given the small range of mean differences in nasalance scores between the age and gender groups, this particular finding should not be overstated. Previous studies that compared age and gender did not find a similar interaction effect $[30,34]$.

\section{Conclusions}

The normative nasalance scores for middle-aged and elderly Brazilian-speakers reported in the present study may serve as a reference for clinical populations, includ- ing patients with velopharyngeal disorders due to late treatment for cleft palate, hearing impairment, cochlear implantation, and acquired motor speech disorders affecting oral-nasal balance in speech. Across the life span, the present study found that female speakers scored on average 2 points higher than males for all speech stimuli. While consistent, this small difference is unlikely to require clinicians to make changes to their practice. Older speakers scored significantly higher than younger speakers for oral and phonetically balanced stimuli. Despite the relatively small differences found, clinicians and researchers may wish to consider a speaker's age and gender when interpreting nasalance scores. More research is needed to further investigate the physiological changes of the vocal tract and, in particular, of the velopharyngeal sphincter across the life span.

\section{Acknowledgements}

This study was supported by the São Paulo Research Foundation - FAPESP (Fundação de Amparo à Pesquisa do Estado de São Paulo; grant No. 2012/23899-6) and by Coordenação de Aperfeiçoamento de Pessoal de Nível Superior (CAPES). The authors thank all the middle-aged and elderly adults who participated in this study.

\section{Statement of Ethics}

The study was approved by the Institutional Review Board at the Universidade Estadual Paulista "Júlio de Mesquita Filho" in Marília, São Paulo, Brazil. All participants provided informed consent according to the procedures approved by the Research Ethics Board at UNESP Marília.

\section{Disclosure Statement}

The authors declare no conflict of interest.

\section{References}

1 Kummer AW: Cleft Palate and Craniofacial Anomalies: Effects on Speech and Resonance, ed 3. Clifton Park, Cengage Learning, 2014.

2 Dalston RM, Neiman GS, Gonzalez-Landa G: Nasometric sensitivity and specificity: a cross-dialect and cross-culture study. Cleft Palate Craniofac J 1993;30:285-291.

3 Mayo CM, Mayo R: Normative nasalance values across languages. ECHO 2011;6:22-32.
4 Stelck EH, Boliek CA, Hagler PH, Rieger JM: Current practices for evaluation of resonance disorders in North America. Semin Speech Lang 2011;32:58-68.

5 Howard BK, Rohrich RJ: Understanding the nasal airway: principles and practice. Plast Reconstr Surg 2002;109:1128-1144; quiz 1145-1146.
6 Kuehn DP, Moller KT: Speech and language issues in the cleft palate population: the state of the art. Cleft Palate Craniofac J 2000;37: $1-35$.

7 Sweeney T, Sell D, O’Regan M: Nasalance scores for normal Irish-speaking children. Cleft Palate Craniofac J 2004;41:168-174. 
8 Zajac DJ: Translating principles of speech science to clinical practice: current and future trends in craniofacial disorders. Perspect Speech Sci Orofac Disord 2008;18:31-40.

9 Brunnegård K, van Doorn J: Normative data on nasalance scores for Swedish as measured on the Nasometer: influence of dialect, gender, and age. Clin Linguist Phon 2009;23:58 69.

10 Fletcher SG: Nasalance vs listener judgements of nasality. Cleft Palate J 1976;13:31-44.

11 Keuning KHDM, Wieneke GH, Dejonckere $\mathrm{PH}$ : Correlation between the perceptual rating of speech in Dutch patients with velopharyngeal insufficiency and composite measures derived from mean nasalance scores. Folia Phoniatr Logop 2004;56:157-164.

12 Nguyen LH, Allegro J, Low A, Papsin B, Campisi P: Effect of cochlear implantation on nasality in children. Ear Nose Throat J 2008; $87: 138,140-143$.

13 Kent RD, Vorperian HK: Speech impairment in Down syndrome: a review. J Speech Lang Hear Res 2013;56:178-210.

14 Green JR, Yunusova Y, Kuruvilla MS, Wang J, Pattee GL, Synhorst L, Zinman L, Berry JD: Bulbar and speech motor assessment in ALS: challenges and future directions. Amyotroph Lateral Scler Frontotemporal Degener 2013; 14:494-500.

15 Soneghet R, Santos RP, Behlau M, Friedrich G, Habermann W, Stammenberger H: Avaliação da nasalância em pacientes submetidos à cirurgia endoscópica funcional dos seios paranasais. Braz J Otorhinolaryngol 2001;67: 50-54.

16 Watterson T, Lewis KE: Test-retest nasalance score variability in hypernasal speakers. Cleft Palate Craniofac J 2006;43:415-419.

17 Lee A, Browne U: Nasalance scores for typical Irish English-speaking adults. Logoped Phoniatric Vocol 2013;38:167-172.

18 El-Kassabi RM, Hassan S, Mesallam TA, Malki KH, Farahat M, Alfaris A: Standardization of nasalance scores in normal Saudi speakers. Logoped Phoniatr Vocol 2015;40:77-85.

19 Seaver EJ, Dalston RM, Leeper HA, Adams LE: A study of nasometric values for normal nasal resonance. J Speech Hear Res 1991;34: 715-721.

20 Awan S, Bressmann T, Poburka B, Roy N, Sharp H, Watts C: Dialectical effects on nasalance: a multicenter, cross-continental study. J Speech Lang Hear Res 2015;58:69-77.

21 Haapanen ML: Nasalance scores in normal Finnish speech. Folia Phoniatr (Basel) 1991; 43:197-203.

22 Trindade IEK, Genaro KF, Dalston RM: Nasalance scores of normal Brazilian Portuguese speakers. Braz J Dysmorphol Speech Hear Disord 1997;1:23-34.

23 Marino VCC, Dutka JCR, de Boer G, Cardoso VM, Ramos RG, Bressmann T: Normative nasalance scores for Brazilian Portuguese using new speech stimuli. Folia Phoniatr Logop 2016;67:238-244.
24 Tachimura T, Mori C, Hirata S, Wada T: Nasalance score variation in normal adult Japanese speakers of Mid-West Japanese dialect. Cleft Palate Craniofac J 2000;37:463-467.

25 Mishima K, Sugii A, Yamada T, Imura H, Sugahara T: Dialectal and gender differences in nasalance scores in a Japanese population. J Craniomaxillofac Surg 2008;36:8-10.

26 Van Lierde KM, Wuyts FL, De Bodt M, Van Cauwenberge P: Nasometric values for normal nasal resonance in the speech of Flemish adults. Cleft Palate Craniofac J 2001;38:112118.

27 Van Lierde KM, Wuyts FL, De Bodt M, Van Cauwenberge P: Age-related patterns of nasal resonance in normal Flemish children and young adults. Scand J Plast Reconstr Surg Hand Surg 2003;37:344-350

28 D'haeseleer E, Bettens K, de Mets S, de Moor V, Van Lierde K: Normative data and dialectical effects on nasalance in Flemish adults. Folia Phoniatr Logop 2015;67:42-48.

29 Hirschberg J, Bók S, Juhász M, Trenovszki Z, Votisky P, Hirschberg A: Adaptation of nasometry to Hungarian language and experiences with its clinical application. Int J Pediatr Otorhinolaryngol 2006;70:785-798.

30 Rochet AP, Rochet BL, Sovis EA, Mielke DL: Characteristics of nasalance in speakers of western Canadian English and French. Can J Speech Lang Pathol Audiol 1998;22:94-103.

31 D'haeseleer E, Depypere H, Claeys S, Van Lierde KM: Nasal resonance in middle-aged women: a multiparameter approach. Ann Otol Rhinol Laryngol 2011;120:575-580.

32 Goodin-Mayeda CE: Nasals and Nasalization in Spanish and Portuguese: Perception, Phonetics and Phonology. Amsterdam, John Benjamins, 2016.

33 Prathanee B, Thanaviratananich S, Pongjunyakul A, Rengpatanakij K: Nasalance scores for speech in normal Thai children. Scand J Plast Reconstr Surg Hand Surg 2003;37:351355.

34 Hutchinson JM, Robinson KL, Nerbonne MA: Patterns of nasalance in a sample of gerontologic subjects. J Commun Disord 1978; 11:469-481.

35 Hoit JD, Watson PJ, Hixon KE, McMahon P, Johnson CL: Age and velopharyngeal function during speech production. J Speech Hear Res 1994;37:295-302.

36 Litzaw LL, Dalston RM: The effect of gender upon nasalance scores among normal adult speakers. J Commun Disord 1992;25:55-64.

37 Kavanagh M, Fee JE, Kalinowiski J: Nasometric values for three dialectal groups within the Atlantic provinces of Canada. J Speech Lang Pathol Audiol 1994;18:7-13.

38 Mayo R, Floyd LA, Warren DW, Dalston RM, Mayo C: Nasalance and nasal area values: cross-racial study. Cleft Palate Craniofac J 1996;33:143-149.
39 van Doorn J, Purcell A: Nasalance levels in the speech of normal Australian children. Cleft Palate Craniofac J 1998;35:287-292.

40 Nichols AC: Nasalance statistics for two Mexican populations. Cleft Palate Craniofac J 1999;36:57-63

41 Okalidou A, Karathanasi A, Grigoraki E: Nasalance norms in Greek adults. Clin Linguist Phon 2011;25:671-688.

42 Karakoc O, Akcam T, Birkent H, Arslan HH, Gerek M: Nasalance scores for normal-speaking Turkish population. J Craniofac Surg 2013;24:520-522.

43 Park M, Baek WS, Lee E, Koh KS, Kim BK, Baek R: Nasalance scores for normal Koreanspeaking adults and children. J Plast Reconstr Aesthet Surg 2014;67:173-177.

44 Holm S: A simple sequentially rejective multiple test procedure. Scand J Stat 1979;6:6570.

45 Bressmann T: Comparison of nasalance scores obtained with the Nasometer, the NasalView, and the OroNasal System. Cleft Palate Craniofac J 2005;42:423-433.

$46 \mathrm{Ha}$ S, Cho SH: Nasalance scores for normal Korean-speaking adults and children: effects of age, vowel context, and stimulus length. Int J Pediatr Otorhinolaryngol 2015;79:12351239.

47 Warren DW, Hairfield WM, Dalston ET: Effect of age on nasal cross-sectional area and respiratory mode in children. Laryngoscope 1990;100:89-93.

48 Tomoda K, Morri S, Yamashita T, Kumazawa T: Histology of human eustachian tube muscles: effect of aging. Ann Otol Rhinol Laryngol 1984;93(pt 1):17-24.

49 Mahne A, El-Haddad G, Alavi A, Houseni M, Moonis G, Mong A, Hernandez-Pampaloni M, Torigian DA: Assessment of age-related morphological and functional changes of selected structures of the head and neck by computed tomography, magnetic imaging, and positron emission tomography. Semin Nucl Med 2007;37:88-102.

50 Schötz S: Acoustic analysis of adult speaker age; in Müller C (ed): Speaker Classification I, Lecture Notes in Computer Science. Springer, 2007, vol 1, pp 88-107.

51 Kalmovich LM, Elad D, Zaretsky U, Adunsky A, Chetrit A, Sadetzki S, Segal S, Wolf M: Endonasal geometry changes in elderly people: acoustic rhinometry measurements. Gerontol A Biol Sci Med Sci 2005;60:396-398.

52 Yilmaz A, Corey J: Rhinitis in the elderly. Clin Allergy Immunol 2007;19:209-219.

53 Zajac DJ: Velopharyngeal function in young and older adult speakers: evidence from aerodynamic studies. J Acoust Soc Am 1997;102: 1846-1851

54 Bundy EL, Zajac DJ: Estimation of transpalatal nasalance during production of voiced stop consonants by noncleft speakers using an oral-nasal mask. Cleft Palate Craniofac J 2006; 43:691-701. 